\title{
Efeito de baixa temperatura e do carbureto de cálcio na emergência de túberas-semente do inhame.
}

\author{
Ademar P. Oliveira; Rivan J. Feitosa Júnior; Riselane Lucena A. Bruno \\ ${ }^{1}$ UFPB - CCA, C. Postal 02, 58.397-000 Areia-PB; Email: ademar.@cca.ufpb.br
}

\section{RESUMO}

Com o objetivo de avaliar o efeito da baixa temperatura e do carbureto de cálcio na emergência de túberas-semente de inhame, cultivar Da Costa, foi conduzido um experimento no período de outubro de 1998 a março de 1999, em Areia-PB. Para se avaliar a influência da baixa temperatura sobre a quebra de dormência das túberas-semente, as mesmas foram armazenadas em câmara fria à temperatura de $5^{\circ} \mathrm{C}$ e umidade relativa de $90 \%$ em quatro períodos $(10 ; 15 ; 20$ e 25 dias). Para se avaliar a eficiência do carbureto de cálcio na quebra da dormência das túberas, as mesmas foram acondicionadas em sacos de polietileno preto com carbureto de cálcio na proporção de $60 \mathrm{~g} / \mathrm{kg}$ de túberas e armazenadas em condições de galpão aberto (temperatura média de $27^{\circ} \mathrm{C}$ e umidade de $64 \%$ ), em quatro períodos $(10 ; 15 ; 20$ e 25 dias $)$. Como testemunhas foram utilizadas túberas acondicionadas em sacos de polietileno sem carbureto de cálcio e túberas armazenadas em galpão aberto. Posteriormente, as túberas foram plantadas em canteiros para se avaliar a percentagem de emergência de plantas. O delineamento experimental empregado foi inteiramente casualizado com dez tratamentos, em quatro repetições. A unidade experimental constituiu-se de 20 túberas-semente. A baixa temperatura não induziu a emergência das túberas-semente do inhame em nenhum período de armazenamento, e aos 25 dias, ocorreu apodrecimento das mesmas. Aos 40 dias após o plantio verificou-se aumento na emergência das plantas, em túberas armazenadas durante dez e quinze dias em sacos de polietileno contendo carbureto de cálcio; este aumento foi de $35 \%$ no número de plantas emergidas em relação às túberas-semente acondicionadas em sacos sem carbureto de cálcio e de $38 \%$ em relação às túberassemente armazenadas em galpão aberto.

\author{
ABSTRACT \\ Low temperature and calcium carbide effect on emergence \\ of yam tuber-seeds.
}

To evaluate the effect of low temperature and calcium carbide on the emergence of yam tuber-seeds, Da Costa cv., an experiment was carried out from October, 1998 to March, 1999, in Areia, Brazil. To evaluate the influence of the low temperature on the emergence of yam tuber-seeds, tubers were stored in cold chamber at $5^{\circ} \mathrm{C}$ and relative humidity of $90 \%$ in four periods $(10 ; 15 ; 20$ and 25 days). To evaluate the efficiency of the calcium carbide on breaking dormancy of tubers, the same were conditioned in black polyethylene bags with calcium carbide in the proportion of $60 \mathrm{~g} / \mathrm{kg}$ of roots and stored under conditions of open shed (temperature of $27^{\circ} \mathrm{C}$ and humidity of $64 \%$ ), in four periods (10;15;20 and 25 days). As control there were used tubers conditioned in bags of black polyethylene without calcium carbide and stored in open shed. Afterwards, tubers were planted in beds, to evaluate plant emergence. The experiment was laid out in complete randomized blocks with ten treatments and four replications. The experimental unit was constituted of 20 tuberseeds. The low temperature didn't induce the emergence of yam tuber-seeds in any storage period, and at 25 days, tubers were rotten. At 40 days after planting date, higher emergence occurred in tubers stored in polyethylene bags containing calcium carbide during ten to fifteen days; this increase was of $35 \%$ in the number of emerged plants in relation to the tuber-seeds conditioned in bags without calcium carbide and of $38 \%$ in relation to the tuber-seeds stored under environmental conditions.

(Aceito para publicação em.26 de outubro de 2.001)

$\mathrm{O}$ inhame também conhecido por cará-da-costa, cará-inhame, inhame da costa ou simplesmente cará, possui grande importância sócio-econômica no Nordeste do Brasil, essencialmente, nos Estados de Pernambuco e Paraíba, considerados os maiores produtores em nível nacional. Essa espécie merece especial atenção por ser planta tropical de grande potencial e que poderá contribuir na solução da demanda de alimentos, sobretudo, nas regiões carentes, sendo amplamente utilizado na alimentação de pessoas de todas as classes sociais. Na Paraíba, as áreas produtoras estão concentradas no litoral e na
Microrregião do Agropastoril do Baixo Paraíba, com área plantada de aproximadamente 7,5 mil ha/ano e produção de cerca de 89,1 mil toneladas (Santos, 1996).

A propagação do inhame é feita por túberas-semente ou parte das túberas comuns (Araújo, 1982). Por apresentar dormência, antes do plantio as túberassemente passam por um período de repouso fisiológico, que pode variar de 20 a 80 dias. Esse período depende do tempo e das condições de armazenamento. Após a colheita permanecem em repouso por aproximadamente três meses, antes de iniciar a brotação, em condi- ção de armazenamento em galpão ou plantadas (Santos, 1996; Santos, 1998).

Algumas espécies de inhame apresentam dormência por período muito longo. Esta deve ser quebrada para que não ocorra baixa percentagem de emergência e desuniformidade no plantio, acarretando problemas na condução da lavoura (Santos, 1996).

No inhame, a aplicação de substâncias indutoras de brotação, é uma atividade desconhecida pelos produtores. A literatura não traz referências a esse respeito. Portanto, o emprego de substâncias indutoras de brotação poderá resolver o problema da brotação desuniforme 
Tabela 1. Percentagem de emergência de plantas de inhame aos 10;20;30;40; 50 e 60 dias, em função de túberas-semente armazenadas em condições de galpão e em sacos de polietileno com e sem carbureto de cálcio. Areia, UFPB, 1999.

\begin{tabular}{lccccccc}
\hline \multirow{2}{*}{ Armazenamento } & \multicolumn{7}{c}{ Dias após o plantio } \\
\cline { 2 - 8 } & $\mathbf{1 0}$ & $\mathbf{2 0}$ & $\mathbf{3 0}$ & $\mathbf{4 0}$ & $\mathbf{5 0}$ & $\mathbf{6 0}$ \\
\hline Galpão1 & $10,0 \mathrm{a}$ & $15,0 \mathrm{C}$ & $35,0 \mathrm{ab}$ & $40,0 \mathrm{~b}$ & $40,0 \mathrm{~b}$ & $40,0 \mathrm{~b}$ \\
Sem carbureto1 & $15,0 \mathrm{a}$ & $25,0 \mathrm{bc}$ & $50,0 \mathrm{ab}$ & $50,0 \mathrm{~b}$ & $50,0 \mathrm{~b}$ & $50,0 \mathrm{~b}$ \\
\hline Com carbureto* & $5,0 \mathrm{a}$ & $40,0 \mathrm{ab}$ & $70,0 \mathrm{a}$ & $85,0 \mathrm{a}$ & $85,0 \mathrm{a}$ & $85,0 \mathrm{a}$ \\
10 & $15,0 \mathrm{a}$ & $50,0 \mathrm{a}$ & $75,0 \mathrm{a}$ & $85,0 \mathrm{a}$ & $85,0 \mathrm{a}$ & $85,0 \mathrm{a}$ \\
15 & $5,0 \mathrm{a}$ & $25,0 \mathrm{bc}$ & $35,0 \mathrm{ab}$ & $55,0 \mathrm{~b}$ & $55,0 \mathrm{~b}$ & $55,0 \mathrm{~b}$ \\
20 & $5,0 \mathrm{a}$ & $20,0 \mathrm{C}$ & $20,0 \mathrm{~b}$ & $20,0 \mathrm{C}$ & $20,0 \mathrm{c}$ & $20,0 \mathrm{c}$ \\
\hline 25 & 66,0 & 36,0 & 34,0 & 31,0 & 31,0 & 31,0 \\
\hline CV (\%) & & & &
\end{tabular}

Médias seguidas da mesma letra na coluna não diferem entre si, pelo teste Tukey, a 5\% de probabilidade.

${ }^{1}$ Média de todos os períodos de armazenamento (10,15, 20 e 25 dias).

*Dias de exposição ao carbureto de cálcio.

dos tubérculos, quando há necessidade de se fracionar as túberas-semente. Este fato tem acarretado perdas consideráveis aos produtores pois resulta em morte dos tubérculos, ocasionada por ocorrência de insetos e patógenos no solo e pelas intempéries que danificam as gemas de brotação. Na produção de túberas-semente a colheita deve ser realizada precocemente (sete meses); Entretanto, numa população elevada é difícil o controle da brotação das túberas, ocorrendo a colheita em estádio de maturação muito aquém daquele indicado tecnicamente, o que resulta em prejuízos na produção de túberas comerciais e de túberas-semente.

A aplicação exógena de etileno pode provocar o estímulo da divisão celular resultando na formação de brotações e de raízes adventícias (Felippe, 1979). O carbureto de cálcio é a fonte mais barata de etileno. No entanto, seu emprego na agricultura é mais utilizado na maturação de frutos e na indução de flores no abacaxizeiro (Oliveira et al., 1999). Como indutor de brotação, é muito pouco utilizado. Na batata o seu emprego na proporção de $1,0 \mathrm{~kg} /$ tonelada de batatasemente, tem apresentado bons resultados na indução de brotação, além de ser um método de baixo custo e de fácil aplicação (Lopes et al., 1996).

O emprego da temperatura na superação da dormência de algumas espécies tem sido relatado. A quebra de dormência pode se dar por temperaturas baixas, associadas à umidade e temperaturas altas, aliadas ao ar seco (Carvalho, 1983). O abafamento de tubér- culos estimula a brotação, devido ao aumento da temperatura, diminuição da concentração de oxigênio e aumento da concentração de gás carbônico (Scholt, 1990). A associação de baixas temperaturas com alta umidade estaria relacionada com alterações no equilíbrio entre hormônios promotores e inibidores do crescimento (Webb et al., 1973). Lopes et al. (1996) citam como método satisfatório para forçar a brotação em tubérculos de batatasemente, temperaturas baixas $\left(3 \mathrm{a} 4^{\circ} \mathrm{C}\right) \mathrm{em}$ câmaras frigoríficas com umidade relativa entre $85-90 \%$, em período variando de 90 a 180 dias.

O presente trabalho teve como objetivo avaliar o efeito do carbureto de cálcio e da baixa temperatura na quebra de dormência de túberas-semente do inhame.

\section{MATERIAL E MÉTODOS}

O trabalho foi conduzido na Universidade Federal da Paraíba, em Areia, no período de outubro de 1998 a março de 1999. Utilizaram-se túberas-semente de aproximadamente $250 \mathrm{~g}$ da cultivar Da Costa. As túberas-semente obtidas na própria região de plantio foram colhidas em agosto de 1998 e armazenadas em galpão de alvenaria, com temperatura média de $26^{\circ} \mathrm{C}$ e umidade relativa de $63 \%$, dois meses antes da aplicação dos tratamentos.

Para se avaliar a influência da baixa temperatura sobre a quebra de dormência das túberas-semente, as mesmas foram armazenadas em câmara fria à temperatura de $5^{\circ} \mathrm{C}$ e umidade relativa de $90 \%$ em quatro períodos, 10 (trata- mento 1), 15 (tratamento 2), 20 (tratamento 3 ) e 25 dias (tratamento 4). Visando avaliar a eficiência do carbureto de cálcio na quebra de dormência das túberas, as mesmas foram acondicionadas em sacos de polietileno preto com carbureto de cálcio na proporção de $60 \mathrm{~g} / \mathrm{kg}$ de túberas e armazenadas em condições de galpão aberto (temperatura ambiente média de $27^{\circ} \mathrm{C}$ e umidade de $64 \%$ ), em quatro períodos (10; 15; 20 e 25 dias), originando os tratamentos $(5 ; 6 ; 7$ e 8 , respectivamente). Como testemunhas foram utilizadas túberas acondicionadas em sacos de polietileno sem carbureto de cálcio (tratamento 9) e túberas armazenadas em galpão aberto, para simular as condições de armazenamento de túberas-semente plantadas por produtores de inhame (tratamento 10). Posteriormente as túberas foram plantadas em canteiros previamente confeccionados de $8,0 \times 1,0 \mathrm{~m}$, espaçadas em $0,20 \times 0,10 \mathrm{~m}$. O delineamento experimental foi inteiramente casualizado, com dez tratamentos em quatro repetições e a unidade experimental foi constituída de 20 túberas-semente.

Foi avaliada a percentagem de emergência de plantas aos 10;20;30; 40; 50 e 60 dias após o plantio. Os dados foram submetidos à análise de variância (teste F) e as médias comparadas pelo teste Tukey, ao nível de 5\% de probabilidade.

\section{RESULTADOS E DISCUSSÃO}

A baixa temperatura não quebrou a dormência das tuberas-semente do inhame em nenhum período de 
armazenamento e aos 25 dias ocorreu o apodrecimento das mesmas, indicando que o emprego de temperatura baixa $\left(5^{\circ} \mathrm{C}\right)$ não deve ser recomendado para eliminar a dormência das túberas.

Com relação à emergência, em função do armazenamento de túberas em sacos de polietileno contendo carbureto de cálcio, foram verificadas diferenças significativas entre os períodos de armazenamento das túberas-semente (Tabela 1). Na avaliação da percentagem de emergência de plantas, aos dez dias, não se verificou diferença significativa entre os tratamentos. Aos 20 dias após o plantio, as túberas armazenadas durante quinze dias com uso do carbureto apresentaram maior percentagem de emergência de planta, porém, sem diferir daquelas armazenadas por dez dias. Aos 30 dias após o plantio das túberas, com o uso de carbureto, ocorreu aumento na percentagem de emergência das túberas armazenadas aos dez e quinze dias.

A partir da avaliação realizada aos 40 dias observou-se que a emergência, em todos os tratamentos, foi constante até o final do período da avaliação (60 dias). Os tratamentos correspondentes ao armazenamento das túberas com carbureto de cálcio, por dez e quinze dias, apresentaram gemas com excelente potencial de brotação, o que resultou em maior percentagem de plantas emergidas. $\mathrm{O}$ incremento no número de plantas emergidas em relação às túberas acondicionadas em sacos sem carbureto de cálcio foi de $35 \%$ e, em relação às túberas armazenadas em condições de ambiente natural foi de $38 \%$. Estes percentuais, representam elevação na emergência de 4.865 e 5.282 plantas/ha, respectivamente.

O efeito positivo do uso do carbureto de cálcio sobre a brotação das túberas confirma que este produto está envolvido no processo de aceleração da emergência no inhame. Este fato, pode propiciar ao produtor condições de antecipar o período de emergência em campo das túberas-semente dessa hortaliça, que em condições normais ocorre entre 20 e 80 dias após o plantio, de forma desuniforme, prejudicando a seleção de plantas para obtenção da semente (Santos, 1996).

Para indução da brotação em plantas de inhame, as túberas-semente devem ser acondicionadas em sacos de polietileno com carbureto de cálcio e armazenadas em galpão aberto por quinze dias.

\section{AGRADECIMENTOS}

Os autores agradecem à professora Sheila Costa de Farias (UFPB) pela correção do abstract.

\section{LITERATURA CITADA}

ARAÚJO, F.C. Aspectos sobre o cultivo do caráda-costa. Recife-PE: IPA, agosto, 1982.33 p. (Boletim técnico, 29).

CARVALHO, N.M. Sementes: ciência, tecnologia e produção. Campinas-SP: Fundação Cargill, 1983, 429 p.

FELIPPE, G.M. Etileno. In: FERRI, M.G. Fisiologia vegetal 2, São Paulo: E.P.U., 1979, 392 p.

LOPES, E.B.; SILVA, F.C.P.; MOURA, F.T. Recomendações técnicas para o cultivo da batatinha (Solanum tuberosum L.) no Estado da Paraíba. João Pessoa - PB: EMEPA-PB, 1996. 61 p. (Circular técnica, 07).

OLIVEIRA, E.F.; CHOAIRY, S.A.; LACERDA, J.T.; CARVALHO, R.A.; BARREIRO NETO, M. Recomendações técnicas para o cultivo do abacaxizeiro. In: ABACAXICULTURA CONTRIBUIÇÃO TECNOLÓGICA. EMEPA-PB, p. 37-56, 1999.

SANTOS, E.S. Inhame (Dioscorea spp.): Aspectos Básicos da Cultura. João Pessoa: EMEPA-PB, SEBRAE, 1996. 158 p.

SANTOS, E.S. Sistemas de plantio e tamanhos de túberas-semente de inhame. In: CONTRIBUIÇÃO TECNOLÓGICA PARA A CULTURA DO INHAME NO ESTADO DA PARAÍBA. João Pessoa: EMEPA-PB, p. 27-35, 1998.

SCHOLT, K. Breaking dormancy of seed potatoes; International Potato Course: Production, storage and seed technology. Wageningen: International Agricultural Center, 1990. 4 p.

WEBB, D.P.; VAN STADEN, J.; WAREING, P.F. Seed dormancy. Journal Experimental Botany. v. 24, n. 78, p. 105-116, 1973. 